Article

\title{
Promoting Policy Coherence within the 2030 Agenda Framework: Externalities, Trade-Offs and Politics
}

\author{
Alexander Brand ${ }^{1, *}$, Mark Furness ${ }^{2}$ and Niels Keijzer ${ }^{2}$ \\ ${ }^{1}$ Rhine-Waal University, 47533 Kleve, Germany; E-Mail: alexander.brand@hochschule-rhein-waal.de \\ 2 German Development Institute, 53113 Bonn, Germany; E-Mails: mark.furness@die-gdi.de (M.F.), \\ niels.keijzer@die-gdi.de (N.K.) \\ * Corresponding author
}

Submitted: 28 August 2020 | Accepted: 8 November 2020 | Published: 26 February 2021

\begin{abstract}
The promotion of Policy Coherence for Sustainable Development is one of the 169 targets of the 2030 Agenda, and considered a key means of implementation. The 2030 Agenda, while noble and necessary to put humanity on a sustainable path, has vastly exacerbated the complexity and ambiguity of development policymaking. This article challenges two assumptions that are common in both policy discussions and associated scholarly debates: First, the technocratic belief that policy coherence is an authentically attainable objective; and second, whether efforts to improve the coherence within and across policies make achieving the Sustainable Development Goals more likely. We unpack the conventional 'win-win' understanding of the policy coherence concept to illustrate that fundamentally incompatible political interests continue to shape global development, and that these cannot be managed away. We argue that heuristic, problem-driven frameworks are needed to promote coherence in settings where these fundamental inconsistencies are likely to persist. Instead of mapping synergies ex-ante, future research and policy debates should focus on navigating political trade-offs and hierarchies while confronting the longer-term goal conflicts that reproduce unsustainable policy choices.
\end{abstract}

\section{Keywords}

2030 agenda; European Union; development policy; policy coherence; policy trade-offs; Sustainable Development Goals

\section{Issue}

This article is part of the issue "The 2030 Agenda for Sustainable Development: Transformative Change through Sustainable Development Goals?" edited by Thomas Hickmann (University of Utrecht, The Netherlands), Markus Lederer (Technical University of Darmstadt, Germany), Jens Marquardt (Technical University of Darmstadt, Germany), Sandra Schwindenhammer (Justus Liebig University Giessen, Germany) and Sabine Weiland (Catholic University of Lille, France).

(C) 2021 by the authors; licensee Cogitatio (Lisbon, Portugal). This article is licensed under a Creative Commons Attribution 4.0 International License (CC BY).

\section{Introduction}

Policy Coherence for Sustainable Development (PCSD) has become an integral aspect of the discourse on the 2030 Agenda and the Sustainable Development Goals (SDGs). This reflects the Agenda's central conviction that global sustainable development requires a transformative and differentiated approach, away from 'business as usual' decision-making that perpetuates economically, socially and environmentally unsustainable policy choices.
While central to the 2030 Agenda, the commitment to PCSD is somewhat buried among the 169 targets associated with the 17 SDGs, appearing towards the end as target 17.14. Official pleas for "governments and stakeholders [to] recognise the relevance of PCSD for identifying, understanding and managing interactions among highly interconnected SDGs" (OECD, 2018, p. 13), raise the questions of (1) whether PCSD is really attainable as an objective, and (2) whether efforts to make policies more coherent make achieving the SDGs more likely. 
These questions arise because policy coherence is often framed as a 'win-win,' where complex puzzles could be solved with more logical decision-making, and political or even ideological conflicts of interest can be resolved technocratically (OECD, 2014). The politics of development has mostly been ironed out of debates about policy coherence since the 2030 Agenda was adopted in September 2015. Indeed, most of the 2030 Agenda's many stakeholders in governments, international organisations, the non-governmental 'development industry,' the for-profit private sector, and the world of research and expert commentary, are happy for the PCSD debate to remain technocratic. It is much easier for stakeholders to focus on processes, instruments and institutional mechanisms rather than on taking on the political conflicts and trade-offs that are essential if development deficits are to be addressed, and goals achieved.

The shortcomings of the technocratic approach to coherence have become even more apparent as the Covid-19 pandemic has swept around the world. While 'the science' must drive public health responses, governments have acted in response to political as well as scientific factors as the socio-economic crisis caused by the pandemic has had varying impacts across the world and within countries. The pandemic has also highlighted the 2030 Agenda's internal contradictions. The UN's 2020 Sustainable Development Report noted that the pandemic had stalled progress towards every SDG, and that its impacts were particularly severe in the most political parts of the 2030 Agenda: inclusion, equity and sustainability (UN, 2020a). In an editorial published five years after the adoption of the 2030 Agenda, the journal Nature argued that the Covid-19 pandemic requires a fundamental reappraisal of both the assumptions underlying the Agenda, and the processes that have been put in place to achieve it. Notably, the willingness of nation states to further invest in international cooperation has diminished. Rather than continuing with Covid-19 recovery plans that promote precisely the unsustainable policy choices that the 2030 Agenda seeks to move away from, decoupling the pandemic recovery and the SDGs from economic growth is needed (Nature, 2020).

This article's purpose is normative and agendasetting. We aim to show how PCSD and related ideas of 'manageability' and 'governability' of policy 'interactions' are linked to the implementation of the complex, often ambiguous and sometimes contradictory 2030 Agenda. This overoptimistic understanding of PCSD's potential does the actual implementation of the ambitious 2030 Agenda a disservice. We rather suggest a heuristic approach that acknowledges that development is a political game at every level, and that fundamental political conflicts between certain objectives, and between the actors pursuing them, will persist. This approach emphasises the highly complex relationship between policy processes, that outcomes are integral to policy processes, and that while solid scientific evidence is essential, its availability is neither a necessary nor a sufficient condition for 'development-friendly' decisions. We argue that promoting coherence requires a problemdriven approach, based on a more pragmatic conceptualisation considering the interaction of the policies relevant for achieving specific development objectives. Our focus on navigating policy hierarchies complements other approaches that are ex-ante in focus and seek to identify processes for promoting synergies across policies (Andrews, 2013; Ramalingam, 2013).

The rest of the article is structured as follows. The next section sketches the policy and academic debates about PCSD and re-focuses attention on externalities and trade-offs, which may not be able to be managed to the degree that they disappear. We argue that the illusions associated with PCSD that dominate academic and policy debates on the 2030 Agenda should be recognised. The third section presents a heuristic framework for a different approach to analysing PCSD. Identifying incoherencies is a necessary first step in asking whether there is an available trade-off that could be negotiated, for instance by creating or changing incentives. If this is not the case, it is likely to be due to the power relationships among the actors involved. The quest for coherence, then, becomes a matter of political pressure rather than technocratic management. We offer some examples from development policy practice to illustrate that certain objectives are politically incompatible, and contrast our normative approach with others that focus on prioritisation. The final section concludes that the 2030 Agenda is a political project, which can only be achieved if the political momentum to prioritise it can be created. Future research on policy coherence needs to engage with these political dimensions in a much more serious way.

\section{PCSD and the Implementation of the SDGs}

Current PCSD discussions evolved from the earlier policy coherence for development (PCD) agenda, which emerged in Europe in the 1990s and 2000s. PCD was framed as capturing both deliberate and unintended impacts of other policies on development policy, in the spirit of weeding out incoherencies for the sake of more development-friendly policy solutions (Carbone, 2008). The PCD agenda was, however, reaching its natural limits even before it took up its stronger focus on 'sustainability' (Carbone \& Keijzer, 2016). In the EU context, for example, where PCD had its highest profile and greatest successes, many of the 'low-hanging fruits' of policy incoherence were dealt with not only for development reasons, but also due to political and economic factors unrelated to development such as compatibility with international agreements or competition among interest groups in EU member states. These low hanging fruits included the removal of export subsidies from agricultural products and the conclusion of the 'Everything but Arms' agreement, which granted duty- and quota-free access to the EU Single Market for all products (except armaments) from least developed countries. Both reforms were 
primarily introduced to conform with WTO rules, rather than being driven by concerns about the effects of policy incoherence on development cooperation (Mackie, Klingebiel, \& Martins, 2013).

It is against this background that we need to consider PCSD's potential for supporting the implementation of the ambitious SDG agenda which, from its very inception, included many internal inconsistencies as well as clashes with external policy objectives (Verschaeve, Delputte, \& Orbie, 2016). Following the 2030 Agenda's adoption, 230 indicators were defined to measure progress against the 169 targets associated with the 17 SDGs, a total figure that includes nine indicators that are used in two or three different targets (UN, 2020b). This global framework of indicators was expected to be complemented by indicators at the regional and national levels, to be prepared by the UN member states. For many commentators, an agenda of such scope and width lacked the necessary focus for developing strategic momentum (Glover \& Hernandez, 2016). The fact that the indicator framework was still being refined five years after the Agenda's adoption appeared to support this sceptical view (UN, 2020b).

The 2030 Agenda's complexity seemed to convey the simple truth that, realistically, there was no easy solution to the problem of how to achieve all the SDGs together, in order to meet the 2030 deadline. The Agenda did not come with a recipe for prioritisation and positioned politically incompatible goals such as poverty reduction via economic growth and reducing carbon emissions next to one another (Spaiser, Ranganathan, Swain, \& Sumpter, 2017). This was partly the result of the conscious effort to integrate the poverty reduction and environmental protection agendas, as promoted in the run-up to the Rio +20 Conference in June 2012 when the sustainable development goals were first hinted at (UN General Assembly, 2012). The inconsistencies within the 2030 Agenda are also partly due to the dynamics of the international bargaining processes that produced the SDGs. Linkages between goals were deliberately created via common targets and indicators so that the Agenda itself would be a coherent whole. This was only partly successful, due to the political compromises needed to forge consensus among all UN members (Le Blanc, 2015). The central aspects of the 2030 Agenda that are compatible, such as the goals on health, education and renewable energy, are not grouped or considered as focus areas, which could help address incoherence via progress. The approach to implementing the 2030 Agenda has become a technical, rather than political, process. This has been characterised as 'governance by goals' where states cooperate informally on a non-binding agenda with plenty of room for manoeuvre (Biermann, Kanie, \& Kim, 2017)

Despite this apparent oversight, the PCSD concept was introduced as a key tool for achieving the SDGs. Already during the negotiations for the 2030 Agenda, international policy discussions strongly emphasised the need for concerted and multi-level policy responses
(Dodds, Donoghue, \& Roesch, 2016). The OECD was instrumental in designing and promoting the idea of PCSD during the negotiations. Titled "Policy Coherence for Inclusive and Sustainable Development," one of its position papers made the case for "[a]n updated and broader approach to PCD, based on collective action, common but differentiated responsibilities and mutual benefits, and seeking coherent policies at global, regional and national levels (including advanced, emerging and developing countries)" (OECD, 2015, p. 1). This focus on mobilising different policies and coordinating more closely was markedly different from approaches to promoting coherence in earlier decades, which were mostly driven by direct observations of incoherent policies such as tariff escalation or production-coupled subsidies (ECDPM \& ICEI, 2005).

The PCSD narrative thus posited that there was a way to address complexity and level out inconsistencies in the SDGs through clever policy design. The first step in applying PCSD to the 2030 Agenda was to identify where policies were interacting positively, as synergies, and negatively, so that trade-offs would have to be made between them. In particular, the OECD points out that 'trade-offs' needed full attention: governments should work to "harmonise policies and mainstream the SDGs so that [they] can address interlinked and indivisible goals and targets with full attention given to trade-offs, inter-linkages and complementarities between social, economic and environmental goals" (OECD, 2017, p. 25). This implied that once acknowledged, such trade-offs could be made, and integrated solutions designed "to ensure an effective implementation" (OECD, 2017, p. 88). This narrative has subsequently solidified, with the OECD confidently arguing that:

[A]pplying a PCSD lens can help to identify critical interlinkages among goal areas, manage potential trade-offs, promote synergies, and address negative impacts. Once interlinkages have been identified, frameworks such as the Inclusive Growth Framework and the Framework for Sound Public Governance can help to guide policymakers respond to those interlinkages. (OECD, 2019, p. 51)

Whereas the policy world has deployed PCSD as a conceptual tool for shaping debates about implementation, the academic debate has largely focused on its component concepts such as 'interlinkages,' 'trade-offs' and especially 'synergies.' The focus has mostly been on exploring the potential for identifying and exploiting synergies, and on managing trade-offs as much as possible, rather than acknowledging that they are usually only necessary when political interests are at stake. As Nilsson, Griggs, and Visbeck (2016, p. 320) observe, international negotiations tend to "gloss over tricky trade-offs." And so do most references to PCSD in official documents on implementing the SDG framework published by leading development institutions. It is, however, apparent 
that many academics share this spirit of technocratic do-ability as regards implementing the 2030 agenda. For example, the UN's flagship report on global sustainable development, prepared by a group of eminent scientists, states that "the true transformative potential of the 2030 Agenda can be realised only through a systemic approach that helps identify and manage tradeoffs while maximising co-benefits" (UN, 2019, p. xx). While incompatibilities and clashing goals/policies are often noted in both the academic literature and in scientific reports for policymakers, they are seldom the main focus of discussion. In the few instances when they are, the focus tends to shift towards 'design' questions about how to turn trade-offs into synergies, that invariably leave the reasons why trade-offs have to be made in the first place in the 'black box.'

Such 'SDG optimism' is common in the research on policy interactions. Nilsson et al. (2016, p. 32) consider the main problem to be "policymakers and planners operat[ing] in silos." This places emphasis not on the SDG agenda itself nor on the politics of its implementation, but rather on the structural design of political decision-making systems. Design problems are considered to stand in the way of effectively addressing negative policy interactions and making the most of synergetic linkages. If silo thinking could be overcome, PCSD might contribute to the creation of shared perceptions and enhance the likelihood of identifying trade-offs which were not recognised in the past due to segmented, partial and non-holistic perspectives. Strengthened coordination in the spirit of PCSD could help overcome the most important barriers. Promoting PCSD is, therefore, less about political choices, and more about better dialogue, design, assessment, and coordination processes.

There is a consequent demand for more elaborate tools and techniques for identifying linkages more precisely (Collste, Pedercini, \& Cornell, 2017; Janetschek, Brandi, Dzebo, \& Hackmann, 2020; Nilsson et al., 2018; Nilsson \& Weitz, 2019). This work is, however, based on strong assumptions that trade-offs and their effects are calculable and logical (they can be identified and understood); obvious (a critical mass of decision-makers and their constituencies will agree on what they should be); and a-political (once identified, they can be implemented without using power to overcome opposition). Similarly, the OECD-led policy discussions, and SDG target 17.14 itself, assume that such tools can achieve PCSD when appropriate institutional mechanisms and monitoring systems are in place.

This causal chain is common in the literature: diagnosis (recognition, identification, classification) triggers the sensitisation of actors involved, which is then followed by smarter re-design (holistic approaches; strengthened coordination; appropriate mechanisms), and continuous impact assessment and evaluation. From this approach, ever more optimised and integrated policy solutions will emerge, and the achievement of the SDGs will become more likely.
A good example of this approach can be seen in the work of Scherer et al. (2018, p. 70) who state that:

The mapping of trade-offs [i.e., counteracting SDG interactions] and synergies between different development goals will become increasingly important as policy implementation accelerates....This work provides important information to policymakers....Further quantitative mapping of other interactions will be necessary to explicitly reveal the implicit trade-offs, synergies, and challenges posed by making progress towards multiple SDGs.

Similarly, Barbier and Burgess (2017, p. 2) argue that it is "possible to measure the welfare effects of an increase in the indicator level for one SDG by identifying the trade-offs that occur with achieving another goal." Some observers have gone even further, suggesting that tradeoffs might not only be minimised but resolved, potentially turning them into synergies (Kroll, Warchold, \& Pradhan, 2019). Although such conclusions are not incorrect, and can be useful for informing decision-making, their value for supporting the 2030 Agenda itself is limited at best.

Our scepticism of this reading of the 2030 Agenda and the SDGs is not because we do not share the Agenda's normative purpose and ambition. Nor do we dismiss efforts to improve conceptual understanding and the quality of empirical data on the SDGs, the value of tracing interactions more closely, and the necessity to communicate this new knowledge as a means of raising public consciousness and incentivising policy change. Our point is not that research on synergies and trade-offs is misguided, but rather that it either ignores or downplays essential aspects of an agenda that is inherently political and thus misrepresents the processes through which the agenda must be realised. Indeed, an overoptimistic belief in the potential of steering and managing profoundly political conflicts comes with risks that have to be acknowledged. The SDGs have to be achieved not in research seminars, workshops or laboratories, but in the real world of policy-making, which is about interests, winners and losers, short-term considerations and pressure to take action. This reality is indeed recognised in the preamble to the 2030 Agenda, which refers to "bold and transformative steps" (UN General Assembly, 2015, p. 1). If the 2030 Agenda does not start to demonstrably improve outcomes, it will lose relevance both as a set of guiding principles and as a call for systemic change. This would be disastrous, because the SDGs represent a set of goals that must be reached in the interests of the sustainability of our civilisation.

\section{An Alternative Conceptual Approach: Externalities, Trade-Offs and the Development Policy Cycle}

Rather than searching for the PCSD holy grail, we consider that debates about policy coherence need to re-focus 
on the political realities of the 2030 Agenda. Attempting to redefine complex political questions as synergies, and searching for technical solutions to trade-offs, results in a detached perspective on policy making. Even before the Covid-19 pandemic, the 2030 Agenda was hindered by its misrepresentation as a largely apolitical set of management challenges. Ignoring its profoundly political nature risks that it will become even more marginalised in times of social polarisation, populist denigration of international cooperation, and de-prioritisation of the long-term policy approaches necessary for supporting development.

The question of how to achieve the SDGs can aptly be considered an example of a 'wicked problem.' This is due to several factors, including incoherencies among some of the SDGs themselves, the sheer size of the policy matrix required if all of the goals are to be pursued, and the myriad interests that lie behind the policies that have to be mobilised in support of specific SDGs or parts of the 2030 Agenda, as well as those that undermine progress towards particular SDGs. There is also a 'spatial' element to the 2030 agenda, since progress by one nation state in relation to its priorities regarding one SDG (e.g., electricity generation) may undermine another nation's priorities for progress towards SDGs at a regional level (e.g., river basin management). Since attempts to resolve incoherencies in the policy world require prioritisation, this means dealing with politics, since all priorities that could be set involve political constituencies and their interests.

Figure 1 depicts a simplified conceptualisation of a policy nexus, where two policies interact. Of course, as 'policies' usually involve interest groups, decisionmaking and legislative procedures, executive and implementing actors, and outcomes that are understood both subjectively and in accordance with given 'hard' or objective criteria, such a conceptualisation is not intended to reflect reality. It is, however, useful to visualise some of the most important considerations when we think about coherence.

As depicted in Figure 1, all policies-whether tied to the SDG framework or not-are meant and designed to achieve certain ends. However, at each stage of the policy process from formulation through implementation to outcome, externalities can occur that affect the outcomes of other policies, both positively (i.e., helping another policy to achieve its goal) and negatively (i.e., undermining another policy's prospects of success). Such externalities may be either intentional or unintended in terms of both their design and consequences.

This basic conceptualisation has three key implications: First, it means that the relationship between policy processes is highly complex. Externalities can occur at any of the three stages, and there can be any number of them. When we consider that figure 1 only shows a binary nexus between two policies, the picture becomes incredibly complex very quickly if we add more policy processes, as we inevitably must when applying it to the 2030 Agenda. There is also a temporal dimension which the figure does not capture. Policies $A$ and $B$ will also typically be out of sync with each other: one may be formulated while another has been through several years of implementation. In a multi-policy environment like development cooperation, the notion that any externality may potentially affect any other policy makes the matrix of variables potentially limitless.

A second implication is that outcomes are an integral part of the policy process. Considerations of coherence must, therefore, take into account which outcomes are actually desired, and how these relate to each other. This means that goal hierarchy is inescapable, which logically implies that the priorities of policymakers, and therefore the interests of the constituencies they represent, are crucial. Inherent in the 'PCSD concept' is the normative notion that 'sustainable development' is the priority outcome that other policies have to be coherent with. The coherence of outcomes has to be considered on two dimensions: the context of the SDGs themselves; and the broader context of the coherence of 'sustainable development' with other sets of political objectives. Indeed, PCSD means policy coherence for sustainable development, but there can just as easily be policy coherence for other objectives, such as national security, corporate profits or social welfare, whether in cooperation partner countries or in donor countries. Policymakers are challenged to find ways to address all of these sets of objectives, and they have to respond to the demands of constituent groups that consider their particular interest to be of higher order than the others.

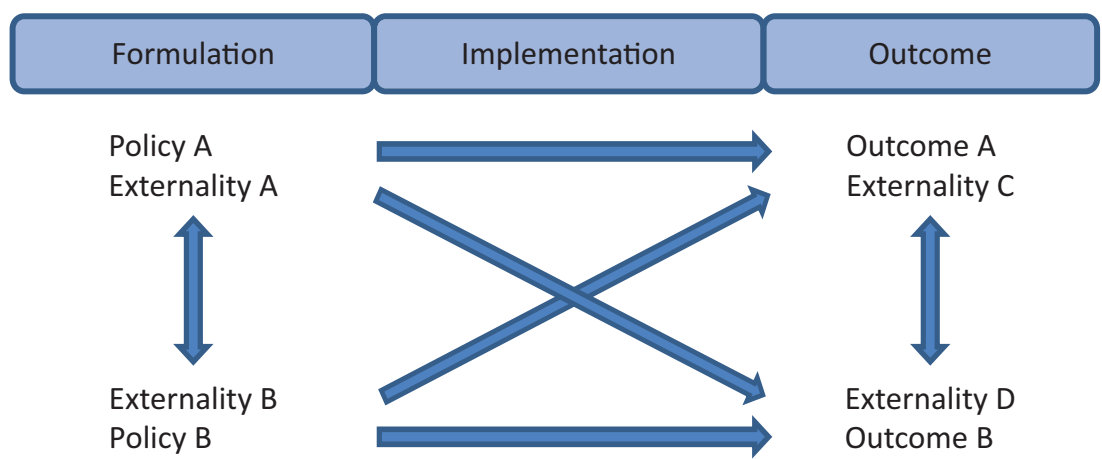

Figure 1. Externalities and outcomes in a policy nexus. 
A third implication is that while better evidence about the impacts of 'non-development' policies on development is valuable, the availability of evidence is neither a necessary nor a sufficient condition for 'development-friendly' decisions. Accordingly, we face a political problem-structure, which is not reducible to considerations of the conceptual and practical incoherence that flows from the 2030 Agenda itself. Rather, it is the incoherence of the constellation of political interests that inevitably influence the chances of implementation of parts of the agenda. This is where the real battle is.

\subsection{Real World Examples of Policy Incoherence}

Examples of wicked problems abound in the real world of development policymaking. The EU's development cooperation programmes in Africa have long provided rich empirical material for policy coherence researchers. The nexuses between trade (especially in agricultural products) and development policy have provided many examples of policies designed by Europeans to benefit their constituencies-European farmers and agribusinessundermining development initiatives, such as technical assistance programmes designed to increase the productive capacity of farmers in African countries, or improve governance systems. One recent example to receive media attention was exports of fat-filled milk powder, including palm oil imported to Europe from Indonesia, to West African countries. Milk powder products are considered essential for food security and therefore carry lower tariffs than other dairy products. According to Oxfam, this particular product can be sold 30\% cheaper than full-fat powdered milk (Matthews \& Soldi, 2019, p. 70). The impact of the cheap, and arguably nutritionally inferior, protein on West African dairy farming has been severe. The smallholder farmers and herders who produce fresh milk in West Africa have been unable to compete and some have been driven into poverty, while the development of local dairy production industries has stalled (Marks \& Livingstone, 2020). A study commissioned by the European Parliament confirmed that while EU agricultural subsidies may have an indirect impact on export prices, there are various domestic producer and consumer preferences that explain the demand for milk powder as opposed to fresh milk (Matthews \& Soldi, 2019, pp. 65-70). There are competing views on how damaging these exports have been for West Africa. The European Commission has argued that they are necessary to make up shortfalls in local production in countries with rapidly increasing populations, and that aid programmes targeting industry capacity in Africa are working. Observers have nevertheless pointed out that European dairy exports, while not subsidised directly, are artificially cheap, and furthermore that they encourage overproduction and low prices for farmers in Europe (SOS Faim Belgium, 2019).

The milk powder debate provides an example where there are at least three priorities that have not been resolved: food security in West Africa, the modernisation of West Africa's dairy industry, and the need to find a market for dairy products that cannot be sold in Europe. Behind these three priorities are the interests of several constituencies with varying levels of power: European dairy giants, European dairy farmers, West African governments, West African smallholders and herders, and West African consumers. These groups disagree about whether trade-offs between the three priorities are needed, and if so where they should be. Must the interests of European agribusiness be sacrificed so that the West African dairy industry can develop? If food security is the highest priority, what is the best way to achieve this-via milk powder imports or via domestic production? The technical solutions to these questions cannot be implemented until the political decision about priorities have been taken.

A second and perhaps more egregious example of the difficulty of achieving PCSD in highly politically sensitive decision-making environments is the debate around the EU's “Emergency Trust Fund for Stability and Addressing Root Causes of Irregular Migration and Displaced Persons in Africa" (EUTF). The migration management trust fund was initiated in 2015, and has a budget of around EUR 5 billion, most of which is Official Development Assistance. The EUTF's documentation does not feature a clear and realistic set of development goals for this aid to be spent on. Rather, its professed aims are expressed in very broad terms: to improve stability and development in Africa, to foster a more inclusive political and economic environment, and to create new opportunities for local populations. The EUTF promises to "help expand and strengthen the rule of law, increase economic productivity and social cohesion, and build resilience for the most vulnerable to natural and man-made disasters" (European Commission, 2015, p. 1). These are, of course, unrealistic expectations for a trust fund, which will never be able to achieve all of this, especially as several decades of EU and bilateral development cooperation have not managed to do so.

It is no coincidence that the EUTF was set up at the same time as irregular migration from Africa to Europe was increasingly being framed as a security threat. Irregular migration across the Mediterranean has become a major humanitarian crisis and a security challenge for Europe in recent years and especially since the tragic civil conflicts in Libya and Syria starting in 2011. Policing and protecting the EU's external maritime borders have become priority topics on the EU agenda, while addressing the 'root causes' of migration and displacement has become a policy mantra. As the constituencies behind security interests are invariably more politically powerful than those behind development interests, efforts to improve the complementarity of security and development policy risk securitisation, with negative implications for core development objectives (Furness \& Gänzle, 2017). 
The Libya coastguard example illustrates the fact that 'sustainable development' often has to compete with, and is sometimes misappropriated for, other political agendas. While most drivers of displacement in Africa are long-term development issues, using development resources to address a phenomenon that has been framed in security terms is, from the PCSD perspective, highly problematic. The EUTF is diverting aid for purposes other than poverty reduction, while still being labelled 'developmental' in intent. It also resembles a clear case of domestic political agendas and constituencies trumping internationalist, development concerns. Lurking behind this are further problems such as a likely shift away from long-term programmes to shortterm 'emergency' measures, effectively ignoring longestablished aid effectiveness principles, and the allocation of funds based on cooperation on migration rather than on development needs (Kipp, 2018).

\subsection{A Pragmatic Approach to Problem-Solving}

Reorienting PCD into PCSD as a key means for promoting the SDGs implies a conceptual and practical shift from business as usual, with development policies formulated, implemented and evaluated by donors on a standalone basis. We argue that PCSD needs to adopt a problem-driven approach, based on a more pragmatic conceptualisation of coherence considering the interaction of all relevant policies for achieving specific development objectives.

Figure 2 suggests that the first stage is to decide what should be achieved in a specific area, for example economy, health, education, or the so-called 'root causes of migration.' This requires a profound understanding of the problem that needs to be solved, which enables the identification of the points of change that have to be addressed. While this may seem obvious to some, doing so is far from simple or easy, as indeed those calling for better understanding of the interactions between goals and policies have pointed out (Janetschek et al., 2020). At this stage especially (although this can happen at any other stage in the cycle), evidence may be gathered and/or selectively used to support choices made, a seemingly technocratic yet inherently political process that has been referred to as "policy-based evidence" (Strassheim \& Kettunen, 2014).

The transition from first to second stage provides opportunities for considering the effects of other policy decisions, which may or may not be addressed depending on political choices, including a willingness to critically assess both the intended and unintended effects of public policy (Keijzer \& Lundsgaarde, 2017). At the second stage, policy tools and resources need to be clearly defined and mobilised. Theoretically, this stage should be relatively technocratic since the overarching political decisions have been taken, but the politics of bureaucratic decision-making is also likely to be influential. The third stage is the implementation phase when initiatives are set in motion and start working. At this stage, problems and setbacks are likely, and iterative adjustments are invariably required (Andrews, 2013). The fourth stage is about completing the cycle and preparing for the next round of an iterative process. While crises can emerge anytime, it is at this stage when longer-term changes are most likely to be made, with intervening factors including the electoral cycle and changing policy hierarchies.

This pragmatic approach to coherence has several implications not only for development policymaking, but also for research. At the strategic level, donor countries need to focus more on setting clear priorities, and outlining coherent policy frameworks defining the contributions expected from development, trade, migration, economic and humanitarian affairs policies in reaching specific SDGs in specific contexts, At the country level, donor countries and institutions such as the EU, UN agencies and the development banks need to set their objectives together with partner countries, coordinate their activities as a rule, and monitor and evaluate their activities effectively. At the conceptual level, there is a need to bring together the political, scientific and civil

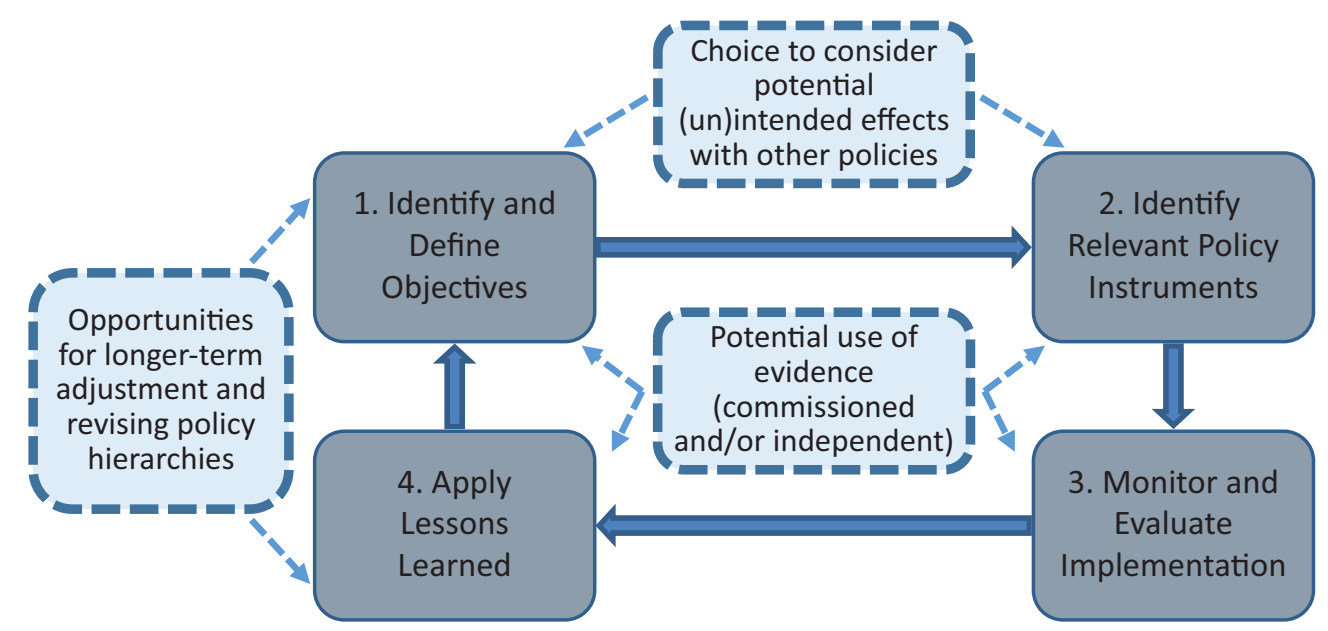

Figure 2. Coherence and the development policy cycle. 
society communities who rarely talk to each other, to (re)conceptualise PCSD in the 2030 Agenda context.

\section{Conceptual and Practical Implications}

In order to judge the potential of our heuristic concept, it is important to note that other observers have used similar terminology, albeit with different meaning(s) attached. The language of externalities and tradeoffs, for instance, has become ubiquitous in the debates about policy coherence and the SDGs (Barbier \& Burgess, 2017; Glover \& Hernandez, 2016; Miola, Borchardt, Neher, \& Buscaglia, 2019). Nilsson and Weitz (2019) also propose a step-by-step model of policymaking, in order to identify, manage, and minimise trade-offs. They distinguish between an input-, a process- and an outputphase, thereby fusing decision-making and implementation into their second stage. At each stage, they describe what needs to be done in order to take advantage of existing policy synergies, as well as to mitigate any arising trade-offs and negative interactions. During the first stage, sufficient cross-sectoral debate is needed, in order for shared actionable understandings of the different interests involved to arise. In other words, a level of consensus between policy-makers needs be generated which presumes that a relatively high level of PCSD is attainable from the very beginning.

During the second stage, the main ambition is to overcome restrictions in the policy process resulting from decision-makers acting in their silos. Institutional reforms to enhance coherence between once discrete departments and extra-governmental stakeholders are recommended (Nilsson \& Weitz, 2019, p. 259). While this is in principle a good idea, we nevertheless question whether political realities allow for such an uncontested redesign of decision-making. The third stage of their model, the output-stage-frames the remainder of policy execution as an exercise in assessing the results of policy implementation. Nilsson and Weitz (2019, p. 260) call for a "revamped impact assessment framework" based on an SDG scorecard, which attempts to contain trade-offs through ongoing assessment of policy outputs over time. As intriguing as this idea is, it implies that minimising trade-offs and realising a maximum from the SDG agenda via policy coherence ranks highly on the agenda of political decision-makers, rather than their (or their constituencies') preferred policy preferences.

Similarly, Miola et al. (2019, p. 15) make the interesting observation that, according to their comprehensive overview of the existing academic literature on policy interlinkages in SDG implementation, the bulk of the assessed linkages can be deemed positive and synergetic in nature. Only about a quarter of the interlinkages they discuss resemble trade-offs. This reading of the potentials and promises of the SDG agenda, with less attention given to challenges and contradictions, contributes to the highly optimistic mood regarding PCSD.
In contrast, we are much more sceptical about the chances of mitigating trade-offs, or minimising negative externalities, through better coordination and assessment procedures. The milk exports example outlined above suggests that the realities of politics, the position of development policy-making in relation to other policies, and the stubborn persistence of incoherencies despite the 2030 Agenda, are not temporary, or possible to resolve technically. Merely identifying potential tradeoffs at the level of objectives, and providing good information about incoherencies that materialise throughout the policy-making process, will not make them disappear.

Another example where similar terminology has been deployed in the literature is the idea of 'prioritisation.' Weitz, Carlsen, Nilsson, and Skånberg (2018) devise a typology for scoring interactions, and they apply network analysis techniques in order to explore how a specific SDG target interacts with other targets in order to provide a more robust basis for SDG policy-making. While we agree that prioritisation must be an essential aspect of policy-making towards achieving at least some SDGs, we have our doubts about whether better knowledge about policy interactions will be one of the main determinants for setting policy priorities. Other aspects of the policy cycle, such as the overwhelming complexity of the issues at hand, time pressure and the political pressure of constituencies, are likely to significantly narrow the space for such smart prioritising. With regard to examples such as the EUTF process outlined above, evidence that measures to restrict migration takes resources away from development programmes and undermine progress towards specific SDGs is unlikely to sway decision-makers, who are responding to pressures to 'do something' in response to migration.

A panel of international experts on sustainable development and development policy has proposed a comprehensive re-think of how to conceptualise and eventually achieve the SDGs (Sachs et al., 2019). Their approach clusters SDG interventions into six domains, premised on the assumptions of "synergetic interventions" (positive interlinkages, with an attainable or already existing high degree of policy coherence) and "workable strategies to manage trade-offs" (Sachs et al., 2019, p. 805). With regard to trade-offs especially, their proposal follows the standard logic: identify and detail the trade-offs, communicate them, involve the stakeholders, prioritise wisely, and the impact of trade-offs will evaporate over time. This assumes that policymakers will be prepared to take the lead, set aside significant resources, overcome opposition through selling the SDGs as a buy-in (Sachs et al., 2019, p. 811), and make it a win-win for everyone involved and affected by the emerging policies.

Sachs et al. (2019, p. 806) argue that: "interventions...are synergistic with no major trade-offs, provided that the leave-no-one-behind principle is applied." Are they? When? Why would those less existentially affected agree to stop pushing their preferences? How do such noble ideas as 'leave-no-one-behind' fit within the 
boundaries and limitations of the policy cycle? Such holistic conceptions are nice on paper, and yet are unworkable in most policy-making settings. They may even help foster a myth of 'yes we can,' while political will is not nearly as uniform and unidirectional as implied. It is time for the 'SDG community' to face up to the political realities inherent in their own Agenda, as well as the many conflicts of interests which persist and cannot be rationalised away through diagnosing, re-designing and repackaging technocratic solutions.

\section{Conclusions}

The 2030 Agenda is too complex, and above all too political, for technocratic solutions to resolve its in-built incoherencies, externalities and trade-offs with other policy areas. The number of potential interactions between the 17 goals and their respective targets is staggering and just understanding the potential scope of interactions is likely to defeat the cognitive capacities of most policymakers, and many researchers as well. Given this level of complexity, it is no shame to admit that a coherent policy framework for achieving the SDGs it is difficult to envisage in conceptual terms, and a virtual impossibility in practical terms.

In contrast to the prevailing narrative in international development institutions and much of the development research field, we consider the PCSD agenda to be illusionary. PCSD has been depicted and sold as a matter of elaborate social engineering (addressing trade-offs and capitalising on synergies etc.), and the many exercises in diagnosing, modelling, mapping, network analysis, sequencing, or transformative clustering convey an optimistic and unifying spirit. Such optimism comes with a price tag, however. The gaps between the rhetoric of the 2030 Agenda and the realities of development policymaking are widening. The continuation of this trend risks caricaturing the SDG process as a pipedream and thereby rendering the 2030 Agenda irrelevant. This has the potential to invite attacks through failures, and fatally undermining the integrity of the whole global development agenda.

In the real world of international development policy-or any other public policy area for that mattercoherence is usually conspicuous by its absence. This does not prevent successes. Often lost in the drive for the efficiency and streamlining inherent in coherence is the important point that positive results can emerge from the messy process of muddling through. The heuristic development policy cycle approach we have outlined suggests that there is certainly room for improvement in this regard, particularly in terms of focusing on specific problems and addressing them using comprehensive, targeted and iterative policy design.

There are multiple externalities resulting from interaction within and between policy domains that do not primarily derive from the SDGs themselves. In such constellations, it seems unlikely that core developmental concerns will be prioritised ahead of issues such as market access, external security or migration management, because all of these have much stronger political constituencies than development does. This implies that achieving the SDGs requires powerful constituencies to accept that their priorities may have to be secondary, which is not something that can happen without political pressure.

In our view, future research on policy coherence needs to engage with these political dimensions in a much more serious way. The 2030 Agenda was difficult to negotiate, and it is proving even more difficult to implement. It is a transformative agenda, and the losers it creates are among the most wealthy and powerful actors on the planet. If it is to make a meaningful contribution to this global transformation, research on policy coherence and the relationships between the SDGs must systematically unpack the constellations of power and interests around these interactions.

\section{Acknowledgments}

We thank the editors of the Special Issue as well as the three anonymous reviewers for their helpful comments and suggestions. Research and publication for this article was partly supported by the German Federal Ministry of Economic Cooperation and Development (BMZ). The views expressed in the article are those of the authors, and do not reflect the position of the BMZ.

\section{Conflict of Interests}

The authors declare no conflict of interests.

\section{References}

Andrews, M. (2013). The limits of institutional reform in development. Cambridge: Cambridge University Press.

Barbier, E. B., \& Burgess, J. C. (2017). The sustainable development goals and the systems approach to sustainability. Economics: The Open-Access, OpenAssessment E-Journal, 11, 1-22.

Biermann, F., Kanie, M., \& Kim, R. (2017). Global governance by goal-setting: the novel approach of the UN sustainable development goals. Current Opinion in Environmental Sustainability, 26, 26-31.

Carbone, M. (2008). Mission impossible: The European Union and policy coherence for development. Journal of European Integration, 30(3), 323-342.

Carbone, M., \& Keijzer, N. (2016). The European Union and policy coherence for development: Reforms, results, resistance. European Journal of Development Research, 28(1), 30-43.

Collste, D., Pedercini, M., \& Cornell, S. (2017). Policy coherence to achieve the SDGs: Using integrated simulation models to assess effective policies. Sustainability Science, 12, 921-931. 
Dodds, F., Donoghue, D., \& Roesch, J. L. (2016). Negotiating the sustainable development goals: A transformational agenda for an insecure world. London: Routledge.

ECDPM, \& ICEI. (2005). EU mechanisms that promote policy coherence for development: A scoping studyTriple C evaluations N 2. Amsterdam: Aksant Academic Publishers.

European Commission. (2015). Emergency Trust Fund for stability and addressing root causes of irregular migration and displaced persons in Africa: Strategic orientation document (Working Paper No. 1, 2). Brussels: European Commission.

Furness, M., \& Gänzle, S. (2017). The securitydevelopment nexus in European Union foreign relations after Lisbon: Policy coherence at last? Development Policy Review, 35(4), 475-492.

Glover, D., \& Hernandez, K. (2016). Integrating sustainable development: A foresight analysis of interactions among competing development challenges (IDS-Evidence Report No. 204). Sussex: IDS.

Janetschek, H., Brandi, C., Dzebo, A., \& Hackmann, B. (2020). The 2030 agenda and the Paris Agreement: Voluntary contributions towards thematic policy coherence. Climate Policy, 20(4), 430-442.

Keijzer, N., \& Lundsgaarde, E. (2017). When 'unintended effects' reveal hidden intentions: Implications of 'mutual benefit' discourses for evaluating development cooperation. Evaluation and Program Planning, 68, 210-217.

Kipp, D. (2018). From exception to rule: The EU Trust Fund for Africa (SWP Research Paper). Berlin: Stiftung Wissenschaft und Politik.

Kroll, C., Warchold, A., \& Pradhan, P. (2019). Sustainable Development Goals (SDGs): Are we successful in turning trade-offs into synergies? Palgrave Communications, 5(140), 1-11.

Le Blanc, D. (2015). Towards integration at last? The sustainable development goals as a network of targets. Sustainable Development, 23, 176-187.

Mackie, J., Klingebiel, S., \& Martins, P. (2013). European report on development 2013: Post-2015-Global action for an inclusive and sustainable future. Brussels: European Commission.

Marks, S., \& Livingstone, E. (2020, August 12). The EU milk lookalike that is devastating West Africa's dairy sector. Politico. Retrieved from https:// www.politico.eu/interactive/the-eu-milk-lookalikethat-is-devastating-west-africas-dairy-sector

Matthews, A., \& Soldi, R. (2019). Evaluation of the impact of the current CAP on the agriculture of developing countries. European Committee of the Regions. Retrieved from https://cor.europa.eu/en/engage/ studies/Documents/CAP-developing-countries.pdf

Miola, A., Borchardt, S., Neher, F., \& Buscaglia, D. (2019). Interlinkages and policy coherence for the Sustainable Development Goals implementation: An operational method to identify trade-offs and co-benefits in a systemic way. Luxembourg: Publications Office of the European Union.

Nature. (2020). Time to revise the Sustainable Development Goals (editorial). Nature, 583(16), 331-332.

Nilsson, M., \& Weitz, N. (2019). Governing trade-offs and building coherence in policy-making for the 2030 agenda. Politics and Governance, 7(4), 254-263.

Nilsson, M., Griggs, D., \& Visbeck, M. (2016). Policy: Map the interactions between sustainable development goals. Nature, 534(16), 320-322.

Nilsson, M., Chisholm, E., Griggs, D., Howden-Chapman, P., McCollum, D., Messerli, P., Stafford-Smith, M. (2018). Mapping interactions between the sustainable development goals: Lessons learned and ways forward. Sustainability Science, 13, 1489-1503.

OECD. (2014). Better policies for development 2014: Policy coherence and illicit financial flows. Paris: OECD.

OECD. (2015). Policy coherence for inclusive and sustainable development (OECD and post-2015 Reflections Series, element 8, paper 1). Paris: OECD.

OECD. (2017). Policy coherence for sustainable development 2017: Eradicating poverty and promoting prosperity. Paris: OECD.

OECD. (2018). Policy coherence for sustainable development 2018: Towards sustainable and resilient societies. Paris: OECD.

OECD. (2019). Policy coherence for sustainable development 2019: Empowering people and ensuring inclusiveness and equality. Paris: OECD.

Ramalingam, B. (2013). Aid on the edge of chaos: Rethinking international cooperation in a complex world. Oxford: Oxford University Press.

Sachs, J., Schmidt-Traub, G., Mazzucato, M., Messner, D., Nakicenovic, N., \& Rockström, J. (2019). Six transformations to achieve the sustainable development goals. Nature Sustainability, 2, 805-814.

Scherer, L., Behrens, P., de Koning, A., Heijungs, R., Sprecher, B., \& Tukker, A. (2018). Trade-offs between social and environmental sustainable development goals. Environmental Science \& Policy, 90, 65-72.

SOS Faim Belgium. (2019). Let's not export our problems. Brussels: European Milk Board. Retrieved from http://www.europeanmilkboard.org/fileadmin/ Subsite/Afrika/Brochure_campagnelait_court_ EN.pdf

Spaiser, V., Ranganathan, S., Swain, R. B., \& Sumpter, D. J. T. (2017). The sustainable development oxymoron: Quantifying and modelling the incompatibility of Sustainable Development Goals. International Journal of Sustainable Development \& World Ecology, 24(6), 457-470.

Strassheim, H., \& Kettunen, P. (2014). When does evidence-based policy turn into policy-based evidence? Configurations, contexts and mechanisms. Evidence \& Policy, 10(2), 259-277.

UN. (2019). The Future is now: Science for achieving sustainable development. Global sustainable development report, 2019. New York, NY: UN. 
UN. (2020a). The Sustainable Development Goals report 2020 (July 2020). New York, NY: UN.

UN. (2020b). Global indicator framework for the Sustainable Development Goals and targets of the 2030 agenda for sustainable development (A/RES/71/313, E/CN.3/2018/2, E/CN.3/2019/2, E/CN.3/2020/2). New York, NY: UN. Retrieved from https://unstats. un.org/sdgs/indicators/Global\%20Indicator\%20 Framework\%20after\%202020\%20review_Eng.pdf

United Nations General Assembly. (2012). Resolution adopted by the General Assembly on 27 July 2012: The future we want (A/RES/66/288). New York, NY: UN. Retrieved from https://www.un.org/ga/search/ view_doc.asp?symbol=A/RES/66/288\&Lang=E
United Nations General Assembly. (2015). Resolution adopted by the General Assembly on 25 September 2015: Transforming our world-The 2030 agenda for sustainable development (A/RES/70/1). New York, NY: UN. Retrieved from https://www.un.org/ga/ search/view_doc.asp?symbol=A/RES/70/1\&Lang=E

Verschaeve, J., Delputte, S., \& Orbie, J. (2016). The rise of policy coherence for development: A multicausal approach. The European Journal of Development Research, 28(1), 44-61.

Weitz, N., Carlsen, H., Nilsson, M., \& Skånberg, K. (2018). Towards systemic and contextual priority setting for implementing the 2030 Agenda. Sustainability Science, $13,531-548$.

\section{About the Authors}

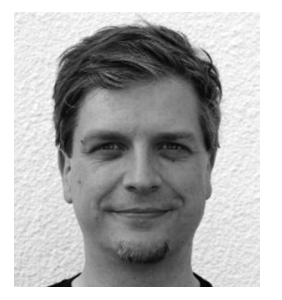

Alexander Brand is Professor of Political Science/International Relations at Rhine-Waal University, Campus Kleve, Germany, where he is teaching in the Master's programme "Sustainable Development Management." Among his research interests are the politics of development assistance as well as sport and international politics.

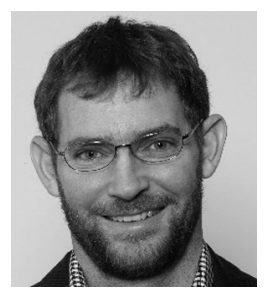

Mark Furness is a Senior Researcher in the research programme "Inter- and Transnational Cooperation" at the German Development Institute. His research and policy advisory work focuses on European Union and German development cooperation, and the Middle East and North Africa region.

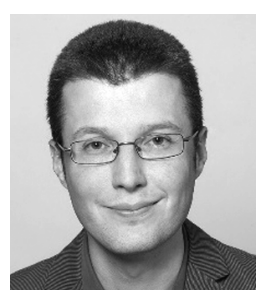

Niels Keijzer is a Senior Researcher in the research programme "Inter- and Transnational Cooperation" at the German Development Institute. His research and advisory work focus on European development cooperation, EU-Africa relations and development effectiveness. 